\title{
Numerical Low-Back Booster Analysis in a 6-Year-Old Infant during a Dolly Rollover Test
}

\author{
I. L. Cruz-Jaramillo (D), ${ }^{1}$ C. R. Torres-San Miguel $\left(\mathbb{D},{ }^{1}\right.$ L. Martínez-Sáez ${ }^{(D)},{ }^{2}$ V. Ramírez-Vela, ${ }^{1}$ \\ and G. M. Urriologoitia-Calderón ${ }^{1}$ \\ ${ }^{1}$ Instituto Politécnico Nacional, Escuela Superior de Ingeniería Mecánica y Eléctrica, \\ Sección de Estudios de Posgrado e Investigación, Unidad Profesional "Adolfo López Mateos" Zacatenco Edificio 5, \\ $2^{\circ}$ Piso Col. Lindavista C. P. 07738, Mexico City, Mexico \\ ${ }^{2}$ Universidad Politécnica de Madrid, Instituto Universitario de Investigación del Automóvil, Campus Sur UPM, \\ Carretera de Valencia (A-3), km7, C. P. 28031, Madrid, Spain
}

Correspondence should be addressed to C. R. Torres-San Miguel; ctorress@ipn.mx

Received 13 March 2019; Accepted 28 December 2019; Published 1 February 2020

Academic Editor: Jose E. Naranjo

Copyright (c) 2020 I. L. Cruz-Jaramillo et al. This is an open access article distributed under the Creative Commons Attribution License, which permits unrestricted use, distribution, and reproduction in any medium, provided the original work is properly cited.

\begin{abstract}
This paper analyzes the possible head and chest injuries, produced in a Hybrid III dummy model of a six-year-old child during a rollover test, while the child uses a passive safety system low-back booster (LBB). Vehicle seats and passive safety systems were modeled with a CAD (Computer Aided Design) software; later, all elements were analyzed using the finite element method (FEM) with LS-DYNA ${ }^{\circledR}$ software. The border conditions were established for each study, in accordance with the regulations of Federal Motor Vehicle Safety Standards (FMVSS), and following the FMVSS 213 standard for the mounting and fastening of the infant, the FMVSS 208 for the dolly methodology test with the vehicle rollover was performed, implementing such analysis under the same conditions for a vehicle Toyota Yaris 2010. The numerical simulations were performed during an interval of 1 second, obtaining data values for periods of 2 milliseconds. This paper examines the efficiency of the system; three case studies were carried out: Study I: vehicle seat belt (VSB); Study II: the LBB system was secured by the seat belt; Study III: the LBB system with ISOFIX anchorage. The values of decelerations for the head and thorax of the infant were obtained, as well as neck flexion and thoracic deflection. The main factor to reduce injuries during a rollover accident is the correct anchorage of the LBB, and this is achieved with the ISOFIX system, since it prevents the independent movement of the LBB, unlike when it is fastened with the seat belt of the vehicle. The results show low levels of head and chest injury when ISOFIX is used because of reduced thoracic deflection during infant retention.
\end{abstract}

\section{Introduction}

Rollover accidents recorded in the US from 1982 to 2015 amounted to 310,809 and generated a death rate of 998,446 people, an average of 3 people per accident. Of the accidents that have occurred from 1982 to 2015, 49.7\% were for light trucks and $50.3 \%$ were for private vehicles; however, private vehicles have accounted for $68 \%$ of the death rate against $32 \%$ for light trucks [1].

The National Institute of Statistics and Geography (INEGI) in Mexico reported that, from 2004 to 2015, there had been 55,485 fatal accidents, 1,108,225 accidents that have only caused minor injuries, and 3,923,857 accidents in which there were only material damage. The largest number of fatal accidents occurred in 2009, with a figure of 5,960 accidents. Regarding nonfatal accidents, the highest rate was in 2007 with 10,732 accidents [2]. In 2014, 380,573 traffic accidents occurred, with 8,233 rollovers, and in 2015, 382,066 traffic accidents occurred, in which 8,368 were rollovers [3].

In traffic accidents that result in a rollover, there is a wide variety, since they depend on several factors and conditions in which the accident occurs, so the scenarios to perform the rollover tests include variations and a wide type of changes 
in the kinematics of the event before and after the rollover of the vehicle [4]. With these tests mentioned, values are obtained on the damages suffered by the vehicle and the injuries suffered by the occupants of the vehicle. This makes it possible to improve and/or modify the structure and materials of the chassis, preventing the roof of the vehicle or the doors from hitting the passengers; in addition, new passive safety systems can be analyzed for the rollovers event, obtaining data to design an exclusive preventing system for vehicular rollover [5].

The NASS-CDS (National Accident Sampling System/ Crashworthiness Data System) proposed a classification of the types of action per rollover [6].

Dolly rollover test is performed under the directive of the Federal Motor Vehicle Safety Standard (FMVSS) 208 and evaluates the behavior of the vehicle in a rollover event, taking into account their previous slowdown, as it affects the structural integrity of the vehicle and its occupants. This kind of test consists on installing the vehicle on a mobile platform, perpendicular to the direction of movement and with $23^{\circ}$ angle of inclination for favor overturning. The platform should move with a constant speed of $30 \mathrm{mph}$ $(13.4112 \mathrm{~m} / \mathrm{s})$, and the vehicle should be motionless in relation to the platform. Subsequently, the platform decelerates to $0 \mathrm{~m} / \mathrm{s}$ over a distance of no more than 3 feet $(0.9144 \mathrm{~m})$, without any change in direction, providing a deceleration of at least $20 \mathrm{G}$ for a minimum of $0.04 \mathrm{~s}$. The test is performed using dummies located inside the vehicle, and these dimensions are then analyzed under different biomechanical values conditions and properly instrumented to against the whole important event recorded on them [7].

Transit injuries are damages to the body caused by sudden exposure to energy concentrations that could exceed body's tolerance margin or factors that interfere with energy exchanges in the body [8].

The neck is exposed to significant mechanical loads when the natural range of extension and flexion of the neck is reached, causing elongation and even tearing in the different ligaments, leading them at an extreme point of the anterior dislocation of the joints. This type of dislocation with "hooking" of the joints is very difficult to reduce and endangers the bulb and spinal cord, with a serious risk of sudden death, quadriplegia, or paraplegia [9].

Nowadays, the improvements applied to child restraint systems (CRS) are in terms of cushions and their fastening systems, implementing the ISOFIX system designed especially for the anchoring of CRS. The ISO (International Organization for Standardization) 13216 describes a universal system for anchoring child restraint systems to vehicles. Specifying the dimensions, general requirements and static resistance requirements of rigid anchors for CRS applied to vehicles, critical dimensions of the accessories, and general requirements for handling. Being a rigid anchor system that holds the child's seat directly to the body of the vehicle, it improves the safety of children. In the beginning, the ISOFIX system only had two anchoring points in the lower part of the seat. Later, a third anchoring point was added, which is in the upper part of the seat, with the purpose of preventing the seat from leaning forward. The objective of this system is to improve the overall safety performance of CRS [10].

The American Academy of Pediatrics (AAP) recommends the use of a booster seat (LBB) for children aged between 4 and 8 years or weighing 40 to 80 pounds (18 to $36 \mathrm{~kg}$ ) [11]. For that reason, the 6-year-old Hybrid III dummy is well within the age and weight range to simulate the children when they use booster seats as recommended by AAP.

This research seeks to quantify the performance of the LBB Evenflo ${ }^{\circledR}$, belonging to groups 2 and 3 (adjustable 3-11 years or $18-49.8 \mathrm{~kg}$ ), with normal anchorage and ISOFIX during the vehicle rollover phenomenon. In methods, three case of studies are presented, where performance and variations of each system show injuries in the infant during the rollover event. Likewise, the design parts of each system, their mechanical properties, and the boundary conditions are established. The outcomes show the vehicle rotation and the kinematic variation with each system analyzed. Accelerations of the thorax and the head are plotted, obtaining the injuries in the head; neck flexion and extension, thorax; and thoracic deflection. With these data, new passive child safety systems can be proposed and designed for rollover accidents.

\section{Materials and Methods}

In order to analyze the behavior of the LBB during vehicle rollovers, three analysis scenarios are simulated with the LSDyna ${ }^{\circledR}$ software version 971 . All the analyzes were mounted with the " $z$ " axis in the translational direction of the rollover, the " $y$ " axis the height, and the " $x$ " axis the depth. Have rotational acceleration on the " $x$ " axis.

The border conditions proposed to develop this study are as follows:

(1) The analysis is carried out with the Hybrid III 6YO FEM model

(2) Catapult was designed to dump the vehicle, and the initial speed and deceleration of the catapult are applied under the requirements of FMVSS 208 standard

(3) Evenflo ${ }^{\circledR}$ LBB for groups 2 and 3 were used to design the LBB system in CAD (Computer Aided Design) software

(4) The numerical analysis was carried out for Toyota Yaris 2010 model, developed by the National Crash Analysis Center (NCAC), which is made up by 771 parts, with 998,218 nodes, and 974,383 elements in which 950,560 are shells, 19,314 are solid, and 4,509 beams

The rear seat of the vehicle was designed in CAD software with the dimensions of a 2010 Yaris Toyota ${ }^{\circledR}$ rear seat, made of two materials: the steel support and the padding. A polypropylene support is used as a connection between the backrest part of the seat and the seat cushion part. In the same way, LBB was designed with the LBB Evenflo ${ }^{\circledR}$ measurements. It consists of a support material, being in this case a polypropylene and padding. The 
mechanical properties of the support steel rear seat, the rigid rods ISOFIX and catapult, are as follows: a density of $7800 \mathrm{~kg} / \mathrm{mm}^{3}$, Young's modulus of $210 \mathrm{GPa}$, elastic limit of $0.6 \mathrm{GPa}$, and Poisson's ratio of 0.3 . The polypropylene mechanical properties are as follows: a density of $9 \times 10^{-7} \mathrm{~kg} /$ $\mathrm{mm}^{3}$, Young's modulus of $1.35 \mathrm{GPa}$, elastic limit of $0.036 \mathrm{GPa}$, and Poisson's ratio of 0.3 [12]. For the cushioning of the seat of the vehicle and LBB, a Foam DAX 55 was chosen whose mechanical properties are a density of $3.5 \times 10^{-8} \mathrm{~kg} / \mathrm{mm}^{3}$, Young's modulus of $5 \times 10^{-5} \mathrm{GPa}$, and Poisson's ratio of 0.31 [13]. For this type of materials, it is necessary to provide the stress-strain curve in LS-DYNA ${ }^{\circledR}$ [14].

The floor mechanical properties of the concrete are as follows: a density of $7.860 \times 10^{-9} \mathrm{~kg} / \mathrm{mm}^{3}$, Young's modulus $200 \mathrm{GPa}$, and Poisson's ratio 0.3.

An $8 \mathrm{~mm}$ mesh size composed of 3D tetrahedral elements is generated for each case using the HyperMesh ${ }^{\circledR}$ V.14.0 software. The total mesh of the catapult was made with 10,650 nodes and 6,750 elements.

The 3-point safety belt design was made according to the seat belt specifications of the selected model, which is $4.7 \mathrm{~cm}$ wide by $1 \mathrm{~mm}$ thickness. The design of the belts was made with the BELTFIT tool in the LS-DYNA ${ }^{\circledR}$ software. The belt was placed in accordance with the standard of the National Highway Traffic Safety Administration (NHTSA) (Figure 1). The design of the belts considers both unidimensional and two-dimensional elements.

The section and the material for the one-dimensional elements were assigned with the default configuration of the safety belt in LS-DYNA ${ }^{\circledR}$. This material has a linear density of $\lambda=5.97 \times 10^{-4} \mathrm{~kg} / \mathrm{mm}$ [15].

The bidimensional elements were assigned as a shell section with a thickness of $1 \mathrm{~mm}$. In addition, these elements were equipped with an elastoplastic material type and with a behavior of linear plasticity parts and the mechanical properties of nylon: a density of $1 \times 10^{-6} \mathrm{~kg} / \mathrm{mm}^{3}$, Young's modulus of $5,333 \mathrm{GPa}$, elastic limit of $0.08 \mathrm{GPa}$, and Poisson's ratio of 0.3 . The loading and unloading curves used in this research represent axial force as a function of seatbelt tension [16]. The anchoring guides for the safety belts and fixing points were placed according to the height and distances of the sedan vehicle considered.

The areas of greatest interest to obtain useful values during the finite element analysis are inside the dummy, especially the head and thorax. A controlled mesh was used with $8 \mathrm{~mm}$ hexahedra ( 8 nodes) for the dummy and $8 \mathrm{~mm}$ $2 \mathrm{D}$ quadratic (4 nodes) elements for the seat belt located on the chest and pelvis to maintain uniformity in the contacts of the nodes (Figure 2).

2.1. Boundary Conditions. The initial speed of the system is $13.34 \mathrm{~m} / \mathrm{s}$ along the " $z$ " axis. The " $y$ " direction corresponds to the vertical direction of the vehicle, and the only force acting is gravity (" $-y$ " axis), with a constant value of $0.00981 \mathrm{~mm} /$ $\mathrm{ms}^{2}$. The peak of this acceleration in the " $z$ " direction is taken from regulation of FMVSS 208 and entered into the software.
For both, the catapult and the floor, a solid section with a rigid-type material is used, as it allows energy transmission due to the properties of the described material, but does not consider deformations, thus saving computational resources. This is done since it is not the main interest to define the microdeformations that will be suffered by the catapult or the floor. Focusing the analysis on the structural damage outfaced by the vehicle subjected to the rollover event.

The contact between tires-catapult and vehicle-floor will be considered for each scenario. The contacts established are seats-dummy and dummy-safety belts. In addition, restrictions are made so that parts of the system move as a whole, in a direction tangential to the plane of the contact, resulting in stresses that are due to the friction between the parts and the stresses that are defined by static and dynamic coefficients of friction of 0.3 and 0.2, respectively [17]. However, the coefficients of static and dynamic friction between the vehicle and the concrete are both 0.85 [18]. The nodal elements (Foam-LBB) are linked so that they behave as a single body.

\section{Results}

The rollover simulation of the vehicle Toyota Yaris 2010 was performed in a one second interval, obtaining data values for every $2 \mathrm{~ms}$. The sequence of the analysis in frontal view for the initial interval is shown: $t=0 \mathrm{~ms}$ to $t=1000 \mathrm{~ms}$ (Figure 3).

In Figure 4, the kinematics of the 3 studies are shown for the dummy behavior in frontal view during the rollover.

3.1. Head. Figure 5 shows the resulting position of the head of the dummy, obtained by the accelerometer located at the center of gravity of the head, which should lead to define acceleration phenomena acting in the head. During the first $380 \mathrm{~ms}$ interval, when a lateral shift occurs, the decelerations are below $10 \mathrm{G}$. After the $400 \mathrm{~ms}$ when the rotation begins, the LBB retention systems generate the maximum decelerations at $435 \mathrm{~ms}$, reaching $42 \mathrm{G}$ the LBB with ISOFIX and $48 \mathrm{G}$ the LBB. While the belt generates a peak at $370 \mathrm{~ms}$ with $25 \mathrm{G}$, when it suddenly drops to $3 \mathrm{G}$ and at 430 , it rises again to $25 \mathrm{G}$; however, the maximum is at $47.5 \mathrm{G}$ occurring at $890 \mathrm{~ms}$. The LBB system with ISOFIX generates the lowest deceleration peak with $42 \mathrm{G}$.

As is shown in Table 1, the HIC15 established by the NHTSA indicates a possible brain injury of around $16 \%$ if the 700 value is reached during a frontal crash event [19]. The VSB causes the highest HIC15 because the seat belt of vehicle does not maintain a correct fit geometry over the infant; on the other hand, the LBB ISOFIX and LBB should have a similar value since the only difference is the anchor, and due to the dimensions and weight of the LBB, it does not move too much when anchored directly with the seat belt.

Figure 6 shows neck flexion and extension of the dummy, obtained by means of the accelerometer located in the center of gravity of the head there of and calculating the movement, by means of rotational displacement, in degrees, of the accelerometer reference system with respect to the 


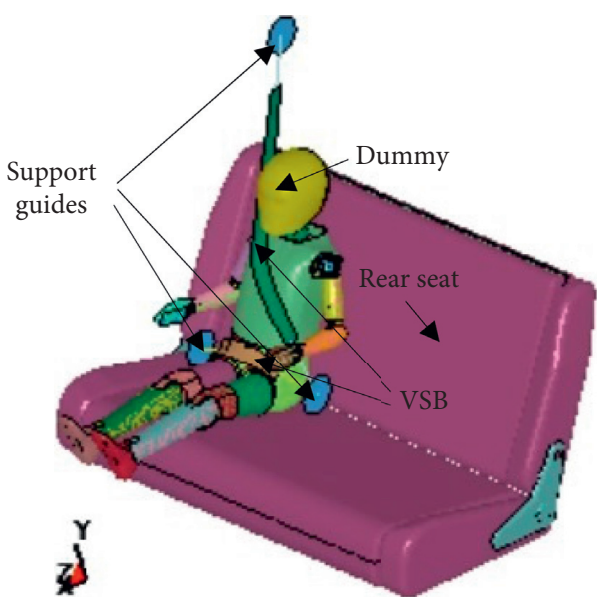

(a)

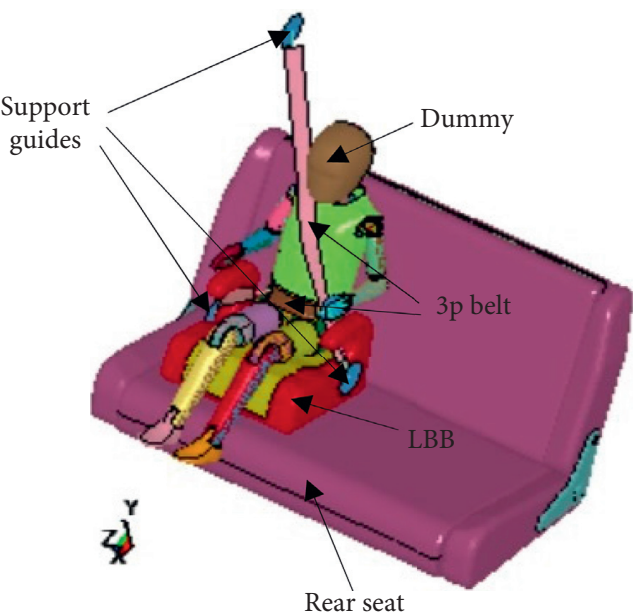

(b)

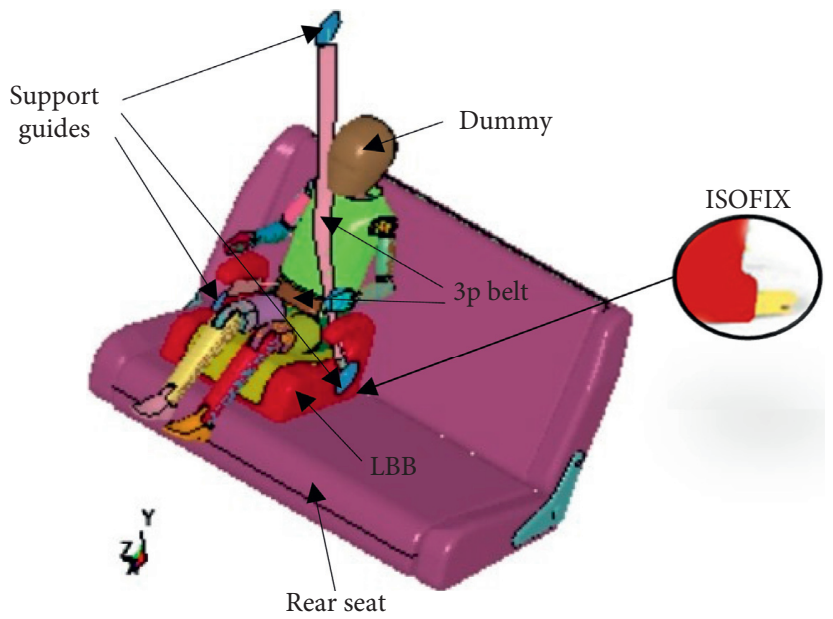

(c)

FIGURE 1: (a) Study (I): only restriction with vehicle safety belt (VSB). The dummy was placed at the back seat of a sedan vehicle and restricted to move by the seat belt implemented. (b) Study II: the dummy was sitting on the LBB and was secured with the $3 p$ seat belt included with the vehicle. (c) Study III: the dummy was sitting in the LBB and secured with the $3 p$ belt and the LBB with the ISOFIX system.
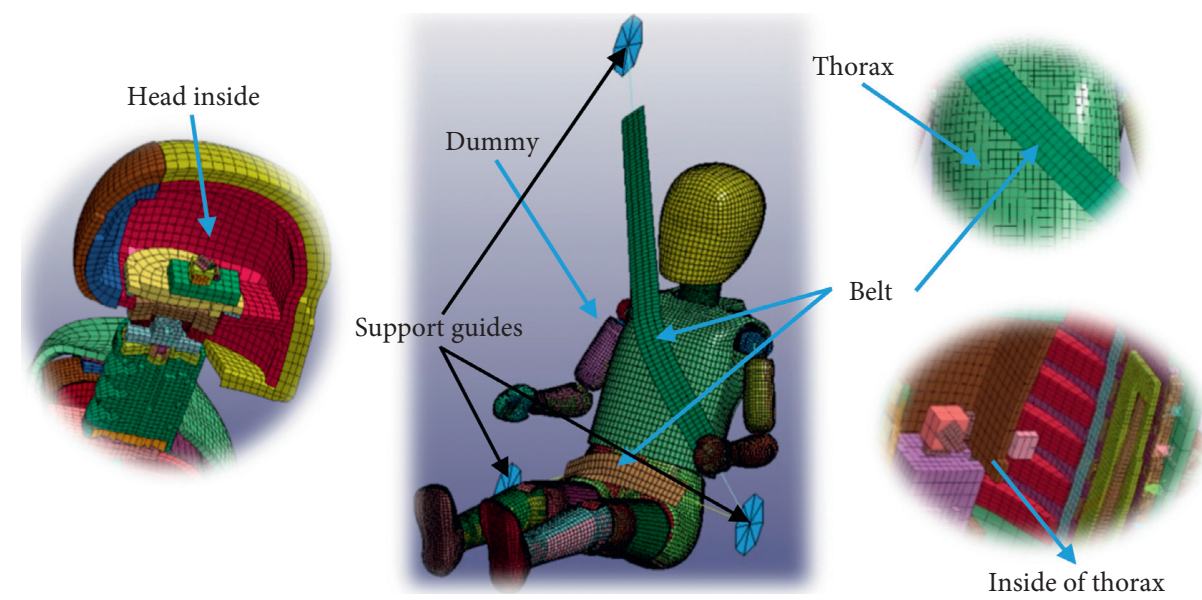

Figure 2: Mesh size composed of $8 \mathrm{~mm}$ 3D hexahedral and 2D quadratic elements. 


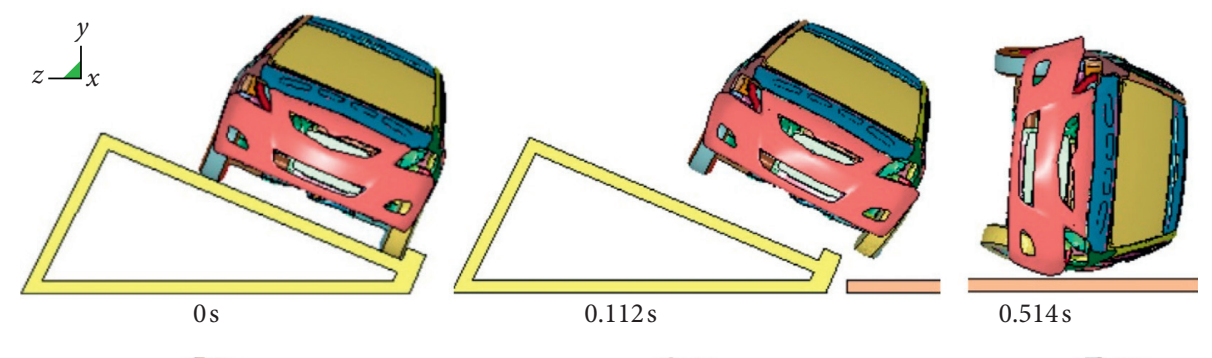

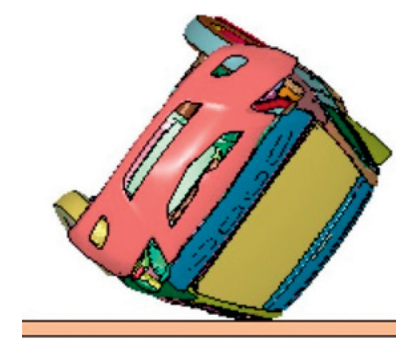

$0.58 \mathrm{~s}$

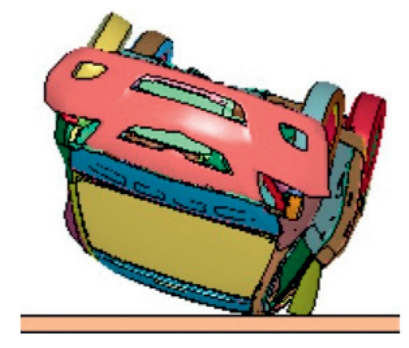

$0.724 s$

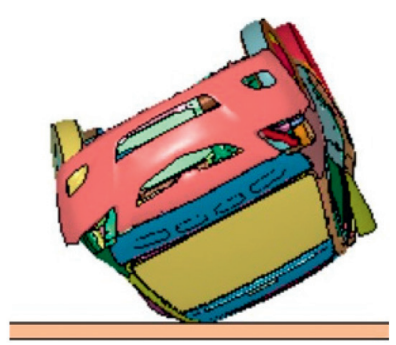

$0.638 \mathrm{~s}$

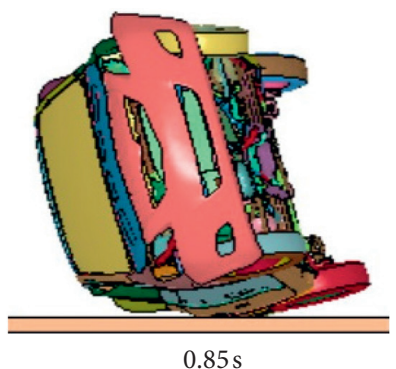

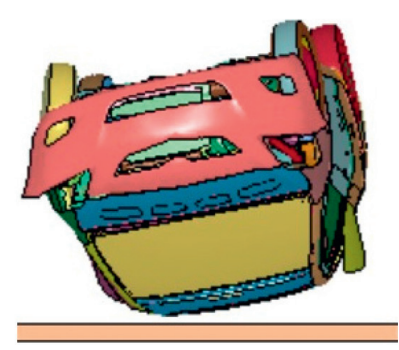

$0.67 \mathrm{~s}$

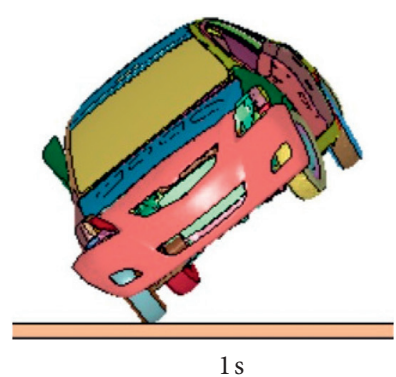

Figure 3: Sequence of images of the rollover analysis of the Toyota Yaris sedan 2010.

base of the neck. Similar flexion values were obtained for the three systems analyzed: $38^{\circ}$ for VSB, $40^{\circ}$ for LBB, and $41^{\circ}$ for LBB ISOFIX. The extension values obtained are $23.5^{\circ}$ for VSB, $16^{\circ}$ for LBB, and $16.1^{\circ}$ for the LBB.

Figure 7 shows the graph for the neck injury criteria (Nij) obtained for each of the systems analyzed during the vehicle rollover event with respect to the Injury Assessment Reference Values (IARV), established by the NHTSA.

Table 2 shows the neck injury criteria (Nij) and is a level 4 neck criterion: NTE (tension-extension), NTF (tensionflexion), NCE (compression-extension), and NCF (compression-flexion) obtained in each of the analyzes performed, as well as the critical values stablished by the NHTSA for a Hybrid III 6-year-old dummy [20].

The LBB ISOFIX generates the highest rates of neck injury criteria, in tension-extension, since the system provides the best retention of the infant, properly supporting the thorax of the infant, causing the head to have a greater displacement in flexion. However, although it generates higher values than the other systems analyzed, the values registered are below than IARV established by the NHTSA. Therefore, LBB ISOFIX protects the infant better without causing serious injuries to the neck.

3.2. Thorax. In the same way, an accelerometer was placed in the thoracic spine of the dummy although the acceleration of the thoracic spine is not quite an appropriate parameter to derive an injury criterion for the thorax, and it has been used in this article to obtain references for the thoracic-restraint capabilities of the systems studied. In Figure 8, a resultant acceleration of the thoracic spine can be observed.

The average accelerations during rollover could reach up to $20 \mathrm{G}$; however, the deceleration peaks amount to more than double, reaching a maximum deceleration peak of $46 \mathrm{G}$ at $890 \mathrm{~ms}$ for the VSB. However, with the LBB and LBB with ISOFIX, it does not exceed $39 \mathrm{G}$, but the ISOFIX has an initial peak of $25 \mathrm{G}$ at $40 \mathrm{~ms}$, and this is due to the rigidity of the system that keeps it fixed to the rear seat of the vehicle, transmitting more directly to the LBB the decelerations that the vehicle undergoes by the catapult during its braking process.

The dummy thoracic deflection obtained in the three analyzes is shown in Figure 9.

Table 3 shows the maximum decelerations of the thorax within an interval of $3 \mathrm{~ms}$ (Clip3m) of the dummy, as well as the Chest Severity Index (CSI) and the thoracic deflection for each system analyzed and the IARV values stipulated by the NHTSA [21].

The LBB system develops an independent movement with respect to the vehicle due to the joint attachment of both system and dummy, through the safety seat belt which generates inertial forces, causing a greater pressure against the thorax of the infant while the infant is being restrained; however, it does not exceed $12 \mathrm{~mm}$ of deflection. In contrast, the VSB and LBB ISOFIX systems have the same movement 
$0 \mathrm{~s}$
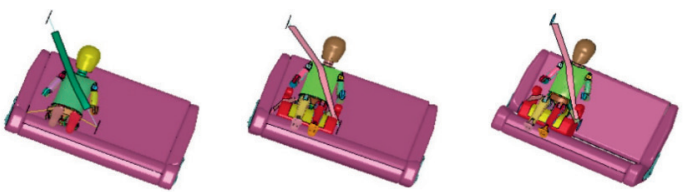

$0.100 \mathrm{~s}$
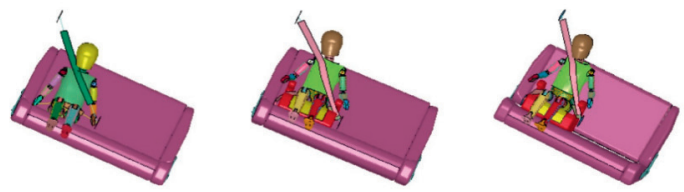

$$
z-y_{x}
$$
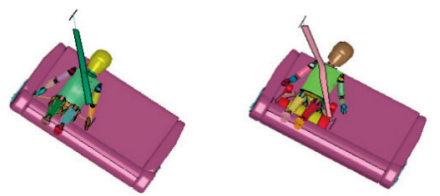

$0.300 \mathrm{~s}$
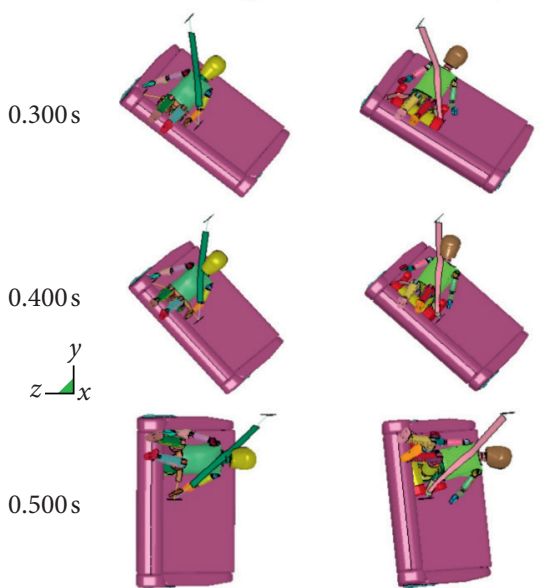

$0.600 \mathrm{~s}$
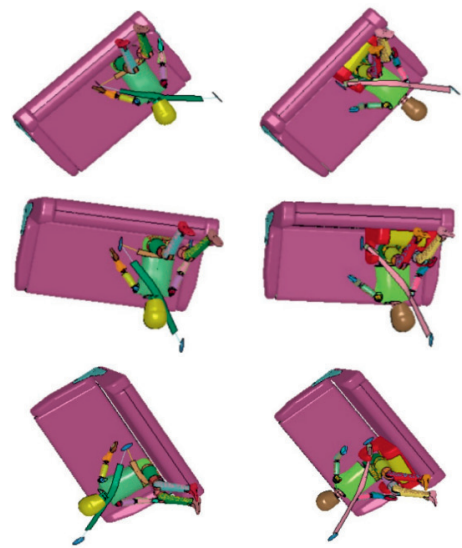

$$
\begin{aligned}
& y \\
& z \\
& \perp
\end{aligned}
$$

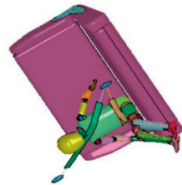

$0.900 s$
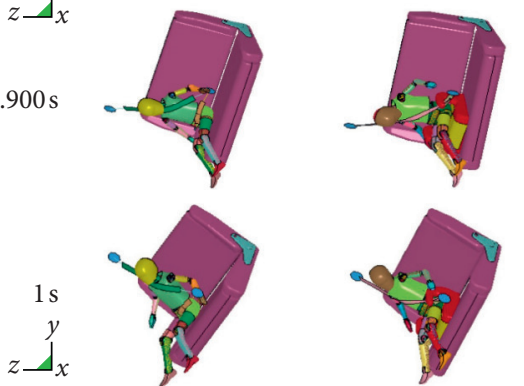

(a)

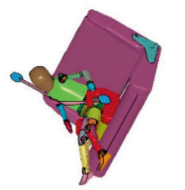

(b)
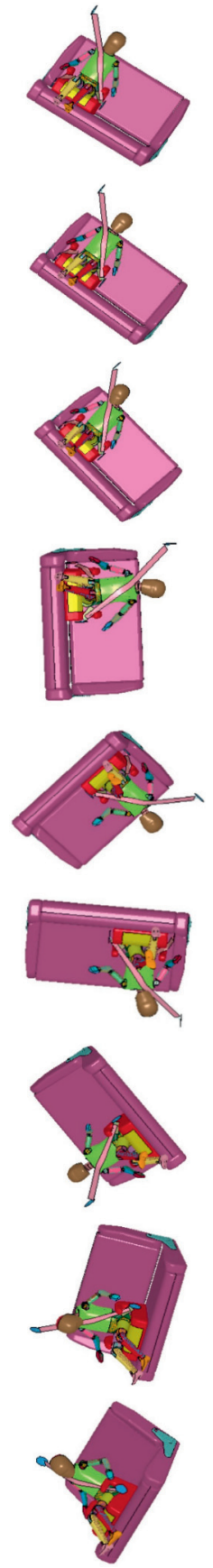

(c)

Figure 4: Dummy kinematics results: (a) VSB, (b) LBB, and (c) LBB with ISOFIX.

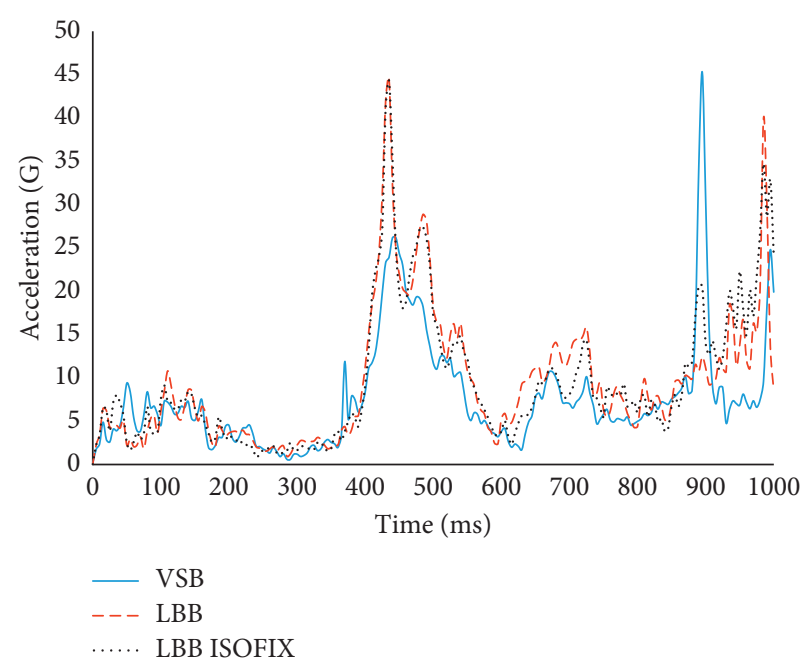

FIGURE 5: Head resultant acceleration.

TABle 1: HIC15.

\begin{tabular}{lccc}
\hline VSB & LBB & LBB ISOFIX & NHTSA \\
\hline 272 & 154 & 156 & 700 \\
\hline
\end{tabular}

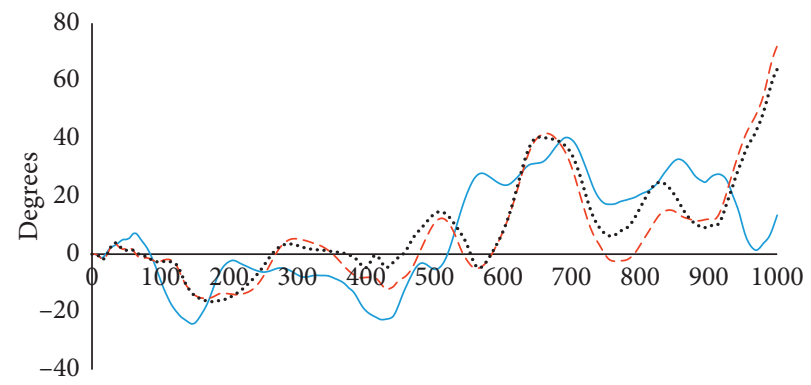

Time (ms)

$$
\begin{array}{ll}
- & \text { VSB } \\
--- & \text { LBB } \\
\ldots \ldots & \text { LBB ISOFIX }
\end{array}
$$

Figure 6: Neck flexion and extension.
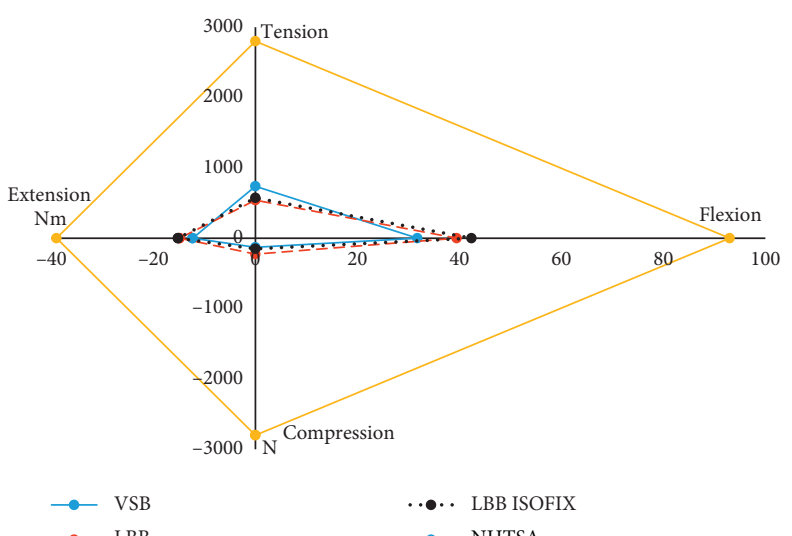

Figure 7: Neck injury criteria. 
TABLe 2: Nij.

\begin{tabular}{lcccc}
\hline & NTE & NTF & NCE & NCF \\
\hline NHTSA & 1.0 & 1.0 & 1.0 & 1.0 \\
VSB & 0.361 & 0.605 & 0.388 & 0.579 \\
LBB & 0.462 & 0.618 & 0.505 & 0.574 \\
LBB ISOFIX & 0.443 & 0.660 & 0.510 & 0.594 \\
\hline
\end{tabular}

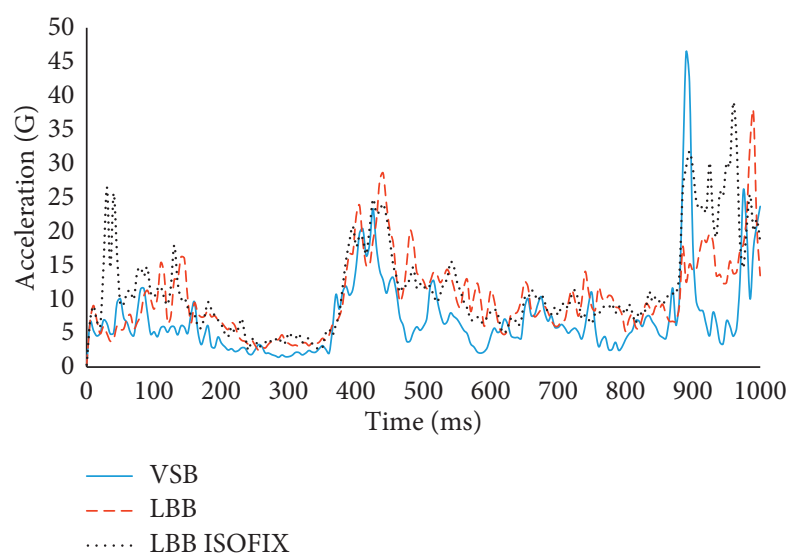

FIgURE 8: Thoracic spine-resultant acceleration.

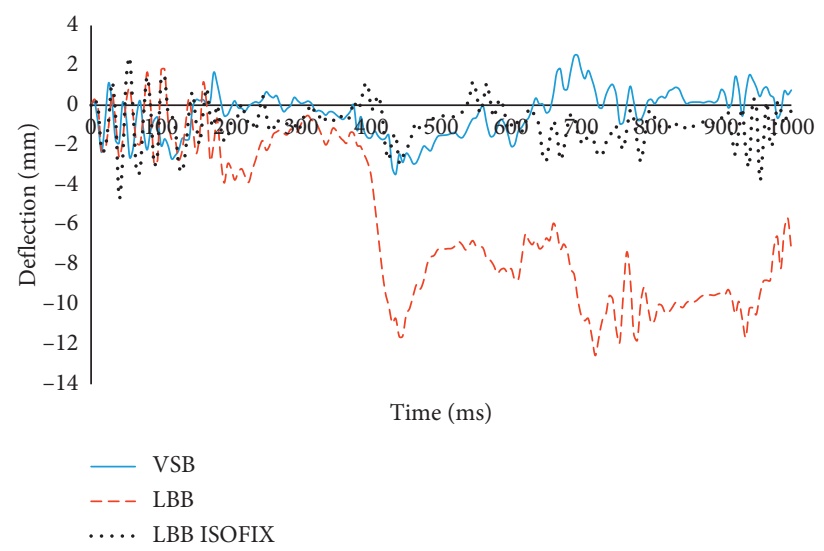

Figure 9: Thoracic deflection.

TABLE 3: Thoracic injury criteria.

\begin{tabular}{lcccc}
\hline & VSB & LBB & LBB ISOFIX & NHTSA \\
\hline CSI & 509.4 & 430.1 & 425.2 & N/A \\
Clip3m (g) & 30.27 & 29.4 & 27.94 & 60 \\
Chest deflection $(\mathrm{mm})$ & 3.1 & 12.6 & 4.6 & 40 \\
\hline
\end{tabular}

as the vehicle, so the seat belt generates less pressure against the thorax. The LBB ISOFIX generates a smaller deflection due to the improvement in the fit for the seat belt of both the pelvic and shoulder portions in the child.

The VSB produces the lowest thoracic deflection, due to a poor belt positioning over the dummy, which causes CSI and Clip $3 \mathrm{~m}$ superior; that is, a poor retention generates a bigger thoracic injury criterion. The ISOFIX LBB produces less thoracic deflection than the LBB; however, the ISOFIX LBB system develops a lower CSI and Clip3m, guaranteeing a good grip that avoids serious chest injuries without having to cause a high thoracic deflection compared to the LBB. The LBB induces the greatest thoracic deflection because the belt must retain both the infant and the LBB setting up a superior pressure on the infant's chest. 

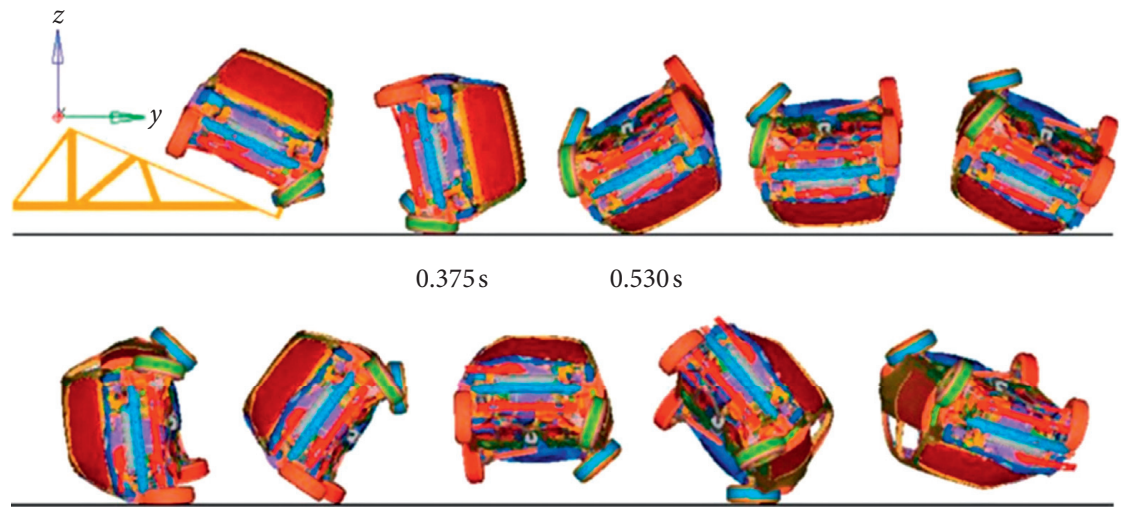

(a)
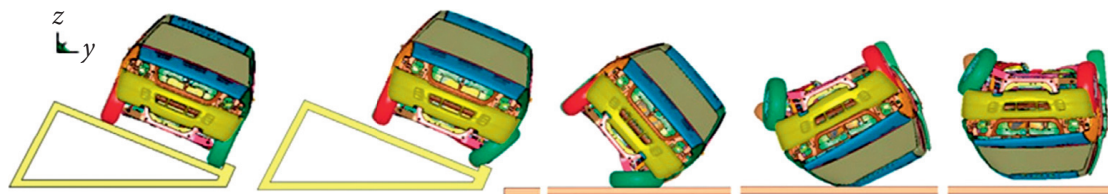

0 s $0.2 \mathrm{~s}$

$0.348 \mathrm{~s}$

$0.495 \mathrm{~s}$

$0.640 \mathrm{~s}$

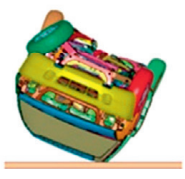

$0.790 \mathrm{~s}$

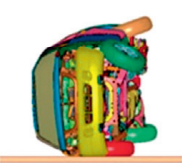

$0.930 \mathrm{~s}$

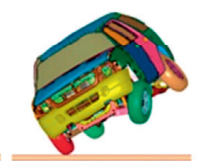

$1.06 \mathrm{~s}$

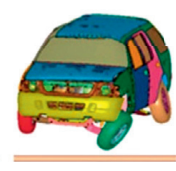

$1.2 \mathrm{~s}$

(b)

Figure 10: Dolly rollover: (a) de Lima and Marczak simulation; (b) Ford Explorer 2003 simulation.

\section{Discussion}

The support of the numerical models was carried out through frontal impact tests, obtaining approximations up to $7.7 \%$ as compared with experimental tests results [22].

The dolly rollover test was validated by comparing with the kinematics results of the Ford Explorer 2003 Version 2, developed by the NCAC, consisting of 791 parts, 632,166 nodes, and 619,161 elements of which 585,418 are hollow, 33,695 are solid, and 48 beams. The test was performed for $1.2 \mathrm{~s}$.

de Lima and Marczak did the simulation for at least $1,500 \mathrm{~ms}$; the first contact of the tire with the ground was in $375 \mathrm{~ms}$, and the first contact of the roof with the ground was in $530 \mathrm{~ms}$ (Figure 10) [23].

In spite of the variations in the time that occur in the contacts against the ground in the analysis reported in by de Lima and Marczak and our analyses, it is worth noting that the kinematics of the movement which is shown in Figure 10 (b) are very similar with respect to the development in Figure 10(a). Under the same conditions, the numerical simulation of the Toyota Yaris 2010 model was carried out, with which the tests for the three studied cases were carried out.

\section{Conclusion}

The numerical analysis was to simulate the nonlinear physical phenomena and give approximate values with respect to the experimental tests at a lower cost and faster. The data obtained in this work allow an optimization of passive child safety systems.

The dolly rollover standard simulates a type of common road accident: lateral sliding and rear rollover, which allows the analysis to be dynamic and realistic, providing good parameters to improve passive safety systems for rollovers.

To provide a better protection to the infant during the rollover phenomenon, a system must be implemented that should allow the correct adjustment of the vehicle safety belt for the infant depending on their age and anthropometry, and this should allow the seat belt to properly hold the infant while minimizing the possibility of injuries occurrence due to the glide of the belt.

Another important factor is that the child protection system has a rigid anchor, thus preventing the system from generating inertial forces, causing greater injuries in the infant due to the energy absorbed by the infant body during the rollover. Therefore, the ISOFIX LBB is the best of the 
three systems analyzed since it provides an adequate adjustment for the seat belt to the infant body, minimizing chest and head injury criteria. Finally, ISOFIX LBB gives greater capabilities to retain the integrity of the infant during the event of rollover.

\section{Data Availability}

The data used to support the findings of this study are available from the corresponding author upon request.

\section{Conflicts of Interest}

The authors declare that they have no conflicts of interest.

\section{Acknowledgments}

The authors acknowledge the financial support for the realization of this work to the Government of Mexico by the National Council of Science and Technology (CONACYT), the Instituto Politécnico Nacional (IPN), and the participation of the biomechanics group of INSIA incorporated to the Polytechnic University of Madrid (UPM), from Spain. The authors also thank the support of projects 1931 and 20196710, as well as an EDI grant, all by SIP/IPN, and also the HERSACA TRA2016-77979-R (MINECO/FEDER, UE) research project funding.

\section{References}

[1] NHTSA, "Traffic safety facts 2015; A compilation of motor vehicle crash data from the fatality analysis reporting system and the general estimates system," Report No DOT HS 812 384, NHTSA, Washington, DC, USA, 2015.

[2] INEGI, Síntesis Metodológica de la Estadística de Accidentes de Tránsito Terrestre en Zonas Urbanas y Suburbanas, INEGI, Aguascalientes, Mexico, 2016.

[3] Instituto Nacional de Estadística y Geografía, 2018, http:// www.inegi.org.mx/sistemas/olap/Proyectos/bd/continuas/ transporte/accidentes.asp? $s=e s t \& c=13159 \&$ proy=atus_accidentes.

[4] C. S. Parenteau, D. C. Viano, M. Shah et al., "Field relevance of a suite of rollover tests to real-world crashes and injuries," Accident Analysis \& Prevention, vol. 35, no. 1, pp. 103-110, 2003.

[5] R. Bardini and M. Hiller, "The contribution of occupant and vehicle dynamics simulation to testing occupant safety in passenger cars during rollover," in Proceedings of the SAE Technical Paper 1999, pp. 1-11, Detroit, MI, USA, March 1999.

[6] N. Cooperider, S. Hammoud, and J. Colwell, "Tipped rollovers," in Proceedings of the SAE Technical Paper 980022, pp. 15-32, Detroit, MI, USA, February 1998.

[7] C. Chou, R. McCoy, and J. Le, "A literature review of rollover test methodologies," International Journal of Vehicle Safety, vol. 1, no. 1-3, pp. 200-237, 2005.

[8] C. Denholm and J. Denholm, "The impact of trauma and critical care: reflections from a practitioner and a patient," Critical Care and Resuscitation, vol. 11, no. 2, pp. 160-161, 2009.

[9] B. García, E. Sandoval, A. Sánchez, and P. González, "Valor pronóstico de las lesiones secundarias de esguince cervical diagnosticadas por resonancia magnética," Revista Mexicana de Medicina Física y Rehabilitación, vol. 14, no. 1, pp. 20-25, 2002.

[10] ISO, Anchorages in Vehicles and Attachments to Anchorages for Child Restraint Systems, ISO, Geneva, Switzerland, 2018, https://www.iso.org/obp/ui/\#iso:std:iso:13216:-1:ed-1:v1:en.

[11] American Academy of Pediatrics, "Addendum-adolescent pregnancy: current trends and issues," Pediatrics, vol. 133, no. 5, pp. 954-957, 2014.

[12] W. Callister, Introducción a la Ciencia e Ingeniería de los Materiales, Vol. 1, John Wiley \& Sons, New York, NY, USA, 2002.

[13] Y. Y. Tay, C. S. Lim, and H. M. Lankarani, "A finite element analysis of high-energy absorption cellular materials in enhancing passive safety of road vehicles in side-impact accidents," International Journal of Crashworthiness, vol. 19, no. 3, pp. 288-300, 2014.

[14] N. Dhole, "Development and validation of a finite element model of a transport aircraft seat under part 25.562 dynamic test conditions," Master thesis, Beachelor of Engineering. University of Pune, Pune, India, 2010.

[15] A. Carrero, Simulación de un Choque Lateral con Dummy con Cinturón mediante LS-DYNA, Universidad Carlos III de Madrid, Madrid, Spain, 2011.

[16] N. Dhole, V. Yadav, and G. Olivares, "Certification by analysis of a typical aircraft seat," in Proceedings of the 12th International LS-DYNA ${ }^{\circledR}$ Users Conference, Dearborn, MI, USA, June 2012.

[17] A. Gavelin, M. Lindquist, and M. Oldenburg, "Modelling and simulation of seat-integrated safety belts including studies of pelvis and torso responses in frontal crashes," International Journal of Crashworthiness, vol. 12, no. 4, pp. 367-379, 2007.

[18] W. Reed and A. Keskin, "Vehicular deceleration and its relationship to friction," in Proceedings of the SAE Technical Paper 1989, pp. 115-120, Detroit, MI, USA, February 1989.

[19] B. G. McHenry, "Head injury criterion and the ATB," in Proceedings of the 2004 ATB Users' Group Conference, pp. 5-8, Salt Lake City, UT, USA, September 2004.

[20] M. Kleinberger, E. Sun, and R. Eppinger, Development of Improved Injury Criteria for the Assessment of Advanced Automotive Restraint Systems, NHTSA, Washington, DC, USA, 1998.

[21] R. Eppinger, E. Sun, and S. Kuppa, Supplement: Development of Improved Injury Criteria for the Assessment of Advanced Automotive Restraint Systems-II, NHTSA, Washington, DC, USA, 2000.

[22] I. L. Cruz-Jaramillo, C. R. Torres-San-Miguel, O. CortesVásquez, and L. Martínez-Sáez, "Numerical low-back booster analysis on a 6-year-old infant during a frontal crash test," Applied Bionics and Biomechanics, vol. 2018, Article ID 2359262, 6 pages, 2018.

[23] A. de Lima and R. J. Marczak, "Simulating occupant injury in rollover crashes. Part 1: a numerical comparison of design procedures for vehicle roof strength assessment," International Journal of Crashworthiness, vol. 20, no. 1, pp. 78-94, 2015. 